\title{
Economic and Social Upliftment of Rural Women through Value Added Products from Aromatic Plants
}

\author{
Charu Gupta ${ }^{*}$ and Dhan Prakash
}

\begin{abstract}
The main objective of the above study was to work for propagation \& popularization of indigenous traditional knowledge of medicinal $\&$ aromatic plants.In the present study, the rural women of villages of Western Uttar Pradesh district Saharanpur were trained on the cultivation and processing of aromatic plants to produce value added products. The aromatic plants that were selected in the project are lemongrass (Cymbopogon flexuosus) and sacred basil (Ocimum sanctum). The plants were selected as per the agro-climatic conditions and the market demand at the project implementation site. The rural women of about 13 villages (in Saharanpur district, Western UP) were imparted training in agro-technology of lemongrass and basil and their products such as lemongrass tea, basil tea, lemongrass leaves powder, basil powder, floor cleaner, face-toner, mosquito repellent spray and agarbatti, herbal hand sanitizer, herbal lemongrass bath, herbal face astringent. The rural women were also trained on the extraction of essential oil from lemongrass and basil through onsite demonstration on mini distillation unit. More than 15 training programs have been conducted till date in which around 600 rural women and farmers were imparted training. The aromatic plants were planted on their unused backyard land such as kitchen garden, community land, Gram Panchayat land etc. without disturbing their conventional crops. The market linkage
\end{abstract}

Amity Institute for Herbal Research \& Studies

(AlHRS), Amity University Noida, India

*Corresponding author; Email:

charumicro@gmail.com was also developed through the project where the rural women got returns from the sale of their lemongrass and basil leaves. This model is being appreciated and is thus being replicated in other adjoining areasof otherdistrict.

\section{KEYWORDS}

Rural women; Women empowerment; Income generation; Aromatic plants; Agro-technology; Value added products

\section{INTRODUCTION}

India has experienced rapid growth and development in the past years in many spheres. This is deplorable considering the important role played by women in the socio-economic growth of the country. The Indian development model has yet to fully incorporate the important role played by women for propelling the socio-economic growth of the country. The greatest problems of rural women in the villages are unemployment, especially in the transition phase; declining or low incomes; economic problems caused by social and political changes; low level of education; lack of extension and knowledge in entrepreneurship; heavy workload both in paid employment and at home; lack of free and inequality in free time compared to men; lack of household services and equipment; deficiencies in the rural infrastructure; social isolation and the low social status (FAO SOFA 2010-11). Due to the lack of specific implementation plans and faulty representations, local communities in these areas have not adequately accepted government and private schemes for the upliftment of rural women. Women have not actively participated in their own emancipation due to their lack of economic independence and 
rampant illiteracy. Poor women, especially from backward communities and lower castes, are mostly illiterate, untrained, and have very little social and economic status (Eyben et al., 2008).

In India, there are over 350 million such people, mainly in rural areas. The unemployed are nearly 200 million people, a great majority of them belonging to these deprived sections of the society. Without meaningful skills, social status, and economic power, they are unable to do any business on their own even with financial assistance. As per the socio-economic survey conducted by government of India in 2011 census, around three-fourth of rural India's highest income is still below Rs.5,000/(Data source: First Post, 2015).

Uneducated lower caste rural women find it almost impossible to initiate any such entrepreneur work without adequate capital, proper training, and on-site daily support.

Besides, farmers have primarily not been inclined towards crop diversification since they have immensely benefited from the *Minimum Support Price (MSP) program of the central government for wheat and rice.For crop diversification to succeed it is essential that the farmer is assured of higher incomes from alternative crops. In order to encourage farmers to undertake such crop diversification it is imperative to incentivize the same along with creating a suitable enabler (Yadava, 2002).

These concerns imply that programmes and activities for rural women's empowerment should at least increase women's selfconfidence and skills; break gender stereotypes; focus on rural labour and labour market issues; improve the quality of services including education and training and promote rural women's collective organisation and participation in progressive networks and alliances (Mangla, 2000).

We undertook this project to address the important issue of women's empowerment and the chief objectives were to promote cultivation of aromatic plants as an employment and income generation tool in rural areas; empowering wiomen and communities on social and development issues through production of value added products from aromatic plants; ensuring employment security for all sectors of rural families both for those who possess land and who are land less and create an economically viable and reproducible model for rural areas.

\section{STUDY DESIGN}

\section{Project Implementation Site}

The project implementation sites wereremote areas of district Saharanpur (Western Uttar Pradesh (UP), India) especially villages of Block - Muzaffrabad and Block Punwarka and covered 13 villages namely Punwarka, Bondaki, Ghunna, Maatki-Zaroli, Maheshwari, Ghanna-Khandi, Bijopura, Bijopuri, Telipura, Mirzapur, Pikki, Salempur and Kheri.The villages were chosen on the basis of sources of their income opportunities and their interest in adopting cultivation of aromatic plants.

\section{Selection of aromatic plants for cultivation}

Depending upon the agro-climatic conditions of the project implementation site i.e. Saharanpur dist. (Western UP, India); the cultivation of lemongrass (Cymbopogon flexuosus) var. Krishnaand basil (Ocimum sanctum) was chosen. The varieties were purchased from the government research institutes i.e. Fragrance \&Flavour Development Centre (FFDC), Kannauj and Central Institute of Medicinal \& Aromatic Plants (CIMAP), Lucknow (UP), India.

\section{Phases of Study}

The project was divided into 3 phases. In the first phase a base line survey of the selected area was initiated and entry point programme to select crops and persons were organized. Through these entry point programme we tried to build confidence about these crops among the rural unemployed women including progressive farmers because farmers are very orthodox in nature and do not easily adopt new technologies regarding crop diversification. 
Gupta and Prakash, European Journal of Social Sciences (EJSS), Vol.1, no.2, DOI:
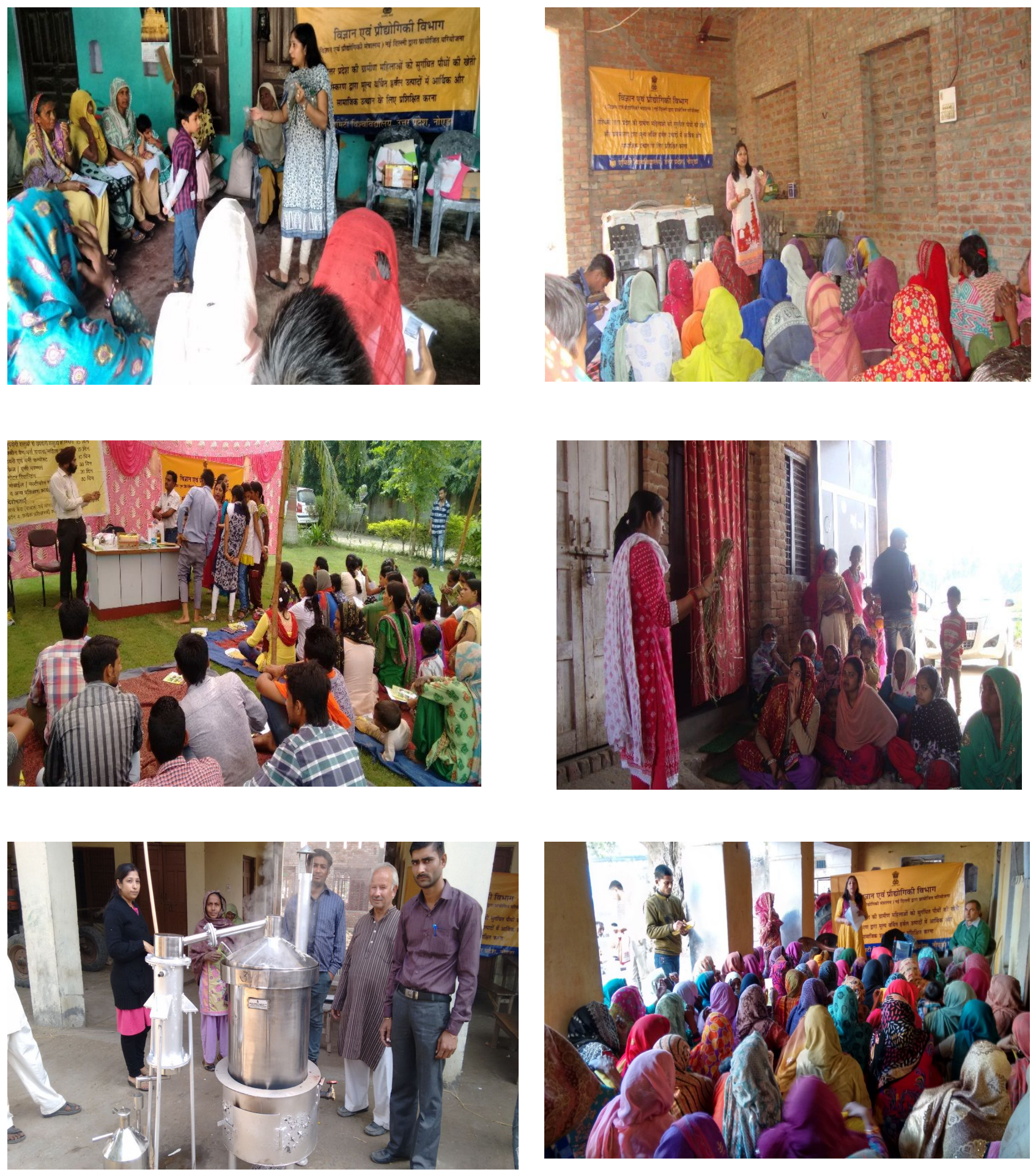

Fig. 1 Demonstration and training in rural areas of Dist. Saharanpur, Uttar Pradesh, India 
In our second phase we provided training to selected persons (especially rural women and progressive farmers) through organizing workshops, training and demonstrations. We distributed free quality planting material of lemongrass slips and basil seeds to the rural women and provided all technical inputs to them on field from land preparation to harvesting and processing. Later on, oil extraction unit was installed for their benefits.

In our third phase the emphasis was laid on quality control, marketing and packaging etc. We identified suitable buyers for the sale of their produce and also formed women self-help groups (SHGs) in the project implementation area.

\section{Plan of Action}

The families of the project target area were contacted by the field workers detailing about the project objectives and targets. They were then asked for their interest to grow lemon grass and basil on their unused kitchen garden land/ backyard land, if any. This was noted in a 'questionnaire' that was prepared for the above purpose. Gram Pradhans of their respective villageswere also requested to provide Gram Panchayat land to the landless families, if possible. Model nursery/garden for Lemon grass and basil were prepared in their backyard and unused land; trainingswere organized on how to grow Lemon grass and basil plants, their medicinal value and importance in health. Demonstration was also given on the extraction of essential oil from lemongrass plants on 'Mini Distillation Units'. Training was imparted to the rural women on the preparation of value-added products from lemongrass and basil (Figure 1).

Besides, pamphlets with brief details about the objectives of the project, training manual in local language (Hindi)indicating the details about the cultivation of selected aromatic plants, process of extraction of essential oil by using mini distillation unit and methods ofpreparation of value-added products from lemongrass and basilwas also distributed free of cost to the rural women and farmers during the training programs.The time schedule of activities is explained in the form of PERT chart giving annual monitorable targets in Fig. 2.

\section{Value Added Products from Aromatic Plants}

The list of value added products that were demonstrated during training to the rural women are Lemon grass Tea bags, Lemon grass tea, Lemon grass powder, basil powder, Herbal Face toner and congestion, Herbal bath scent, Herbal Bath and Compress use, Lemongrass liniment, Herbal mosquito repellent incense sticks and spray, Herbal skin toning cleanser, Lemongrass astringent, Natural Hair oil, Herbal floor cleaner, Herbal tooth powder, basil oil, and Herbal pain balm (Fig. 3).

Self Help Groups (SHGs)of around 4-5 women possessing identifiable qualities of entrepreneurship were counseled and motivated to establish their own aromatic plant farm and prepare, use and sell value added products.

At the end market linkagewas established for buying the lemongrass and basil for income generation. Lemongrass leaves and their slips, whole basil plants have a good market demand and were taken for sale along with their representatives. Due to awareness, encouragement and scope of lemongrass, some progressive rural women have also started planting lemongrass in larger areas up to 1 hectare land.

Due to awareness, encouragement and scope of lemongrass, some progressive rural women have started planting lemongrass in large areas. Some of the progressive women farmers in project implementation site are Smt. Madhu (planted lemongrass in area upto around 16,000 sq. meter), Smt. Angoori (area 800 sq. meter), Smt. Maina Devi (area 2432 sq. meter), Smt. Vinodbala (area 1621 sq. meter) in villages of Dist. Saharanpur (UP). Till date, more than $4000 \mathrm{~kg}$ dried lemongrass leaves were produced and sold (@Rs.15/kg) by rural women of Dist. 
Saharanpur \& earned Rs.60,000/-. This figure is still on rise.

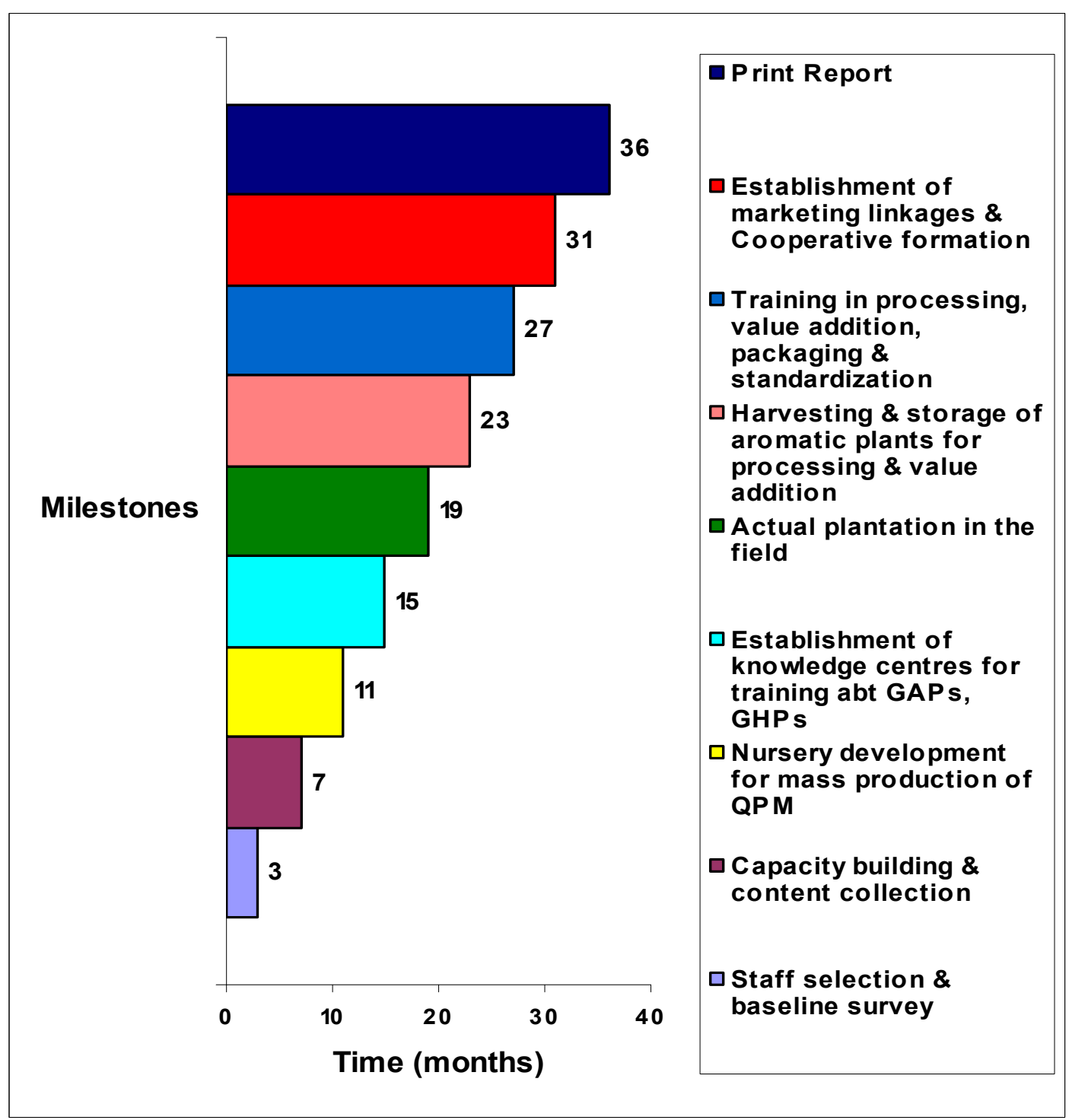

Fig.2 Time schedule of activities giving project milestones

A questionnaire for the rural women was also prepared in their local language (Hindi) to monitor the progress of the project. It comprised of few questions related to the project activity and their satisfaction level with it. Some of the questions were like whether and how they are benefitted from this project (both monetarily and non-monetary gain); what was the average income earned by them after the sale of their produce; whether they have prepared the value added products themselves at home; whether they are using those prepared herbal products; what was theirhealth benefit after using herbal products made chiefly from lemongrass and basil etc. 

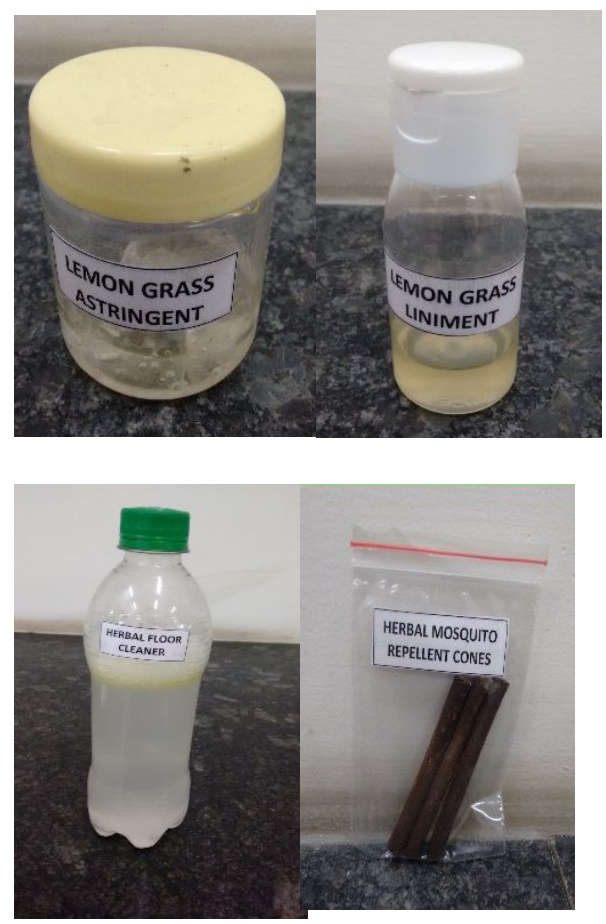
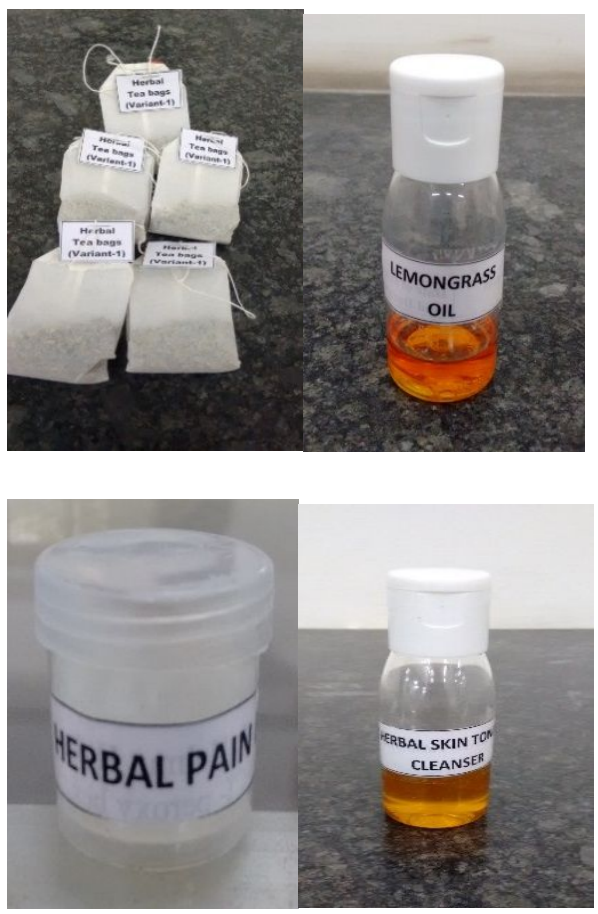

Fig. 3 Demonstration on Value added products prepared from selected aromatic plants

\section{Market Linkage}

The market linkage was established between the growers and the buyers so as to build confidence amongst the rural women and to generate income opportunities. One or two buyers showed interest in the purchase of dried lemongrass and tulsi leaves. The buyers purchased the raw produce sometimes lemongrass slips also at a decent rate thereby generating an average income starting around Rs.500/- depending on the weight of the plant produce. Finally, the money was distributed to the rural women.

\section{Outcome and Impact}

The above study is still ongoing. So till date we can state that impact of project is mainly in terms of socio-economic aspect of beneficiaries i.e. generated awareness in the importance of cultivation of Medicinal \& Aromatic plants amongst rural women including children; increased awareness about the agro- technologies of selected aromatic plants; generated income opportunities by training the rural women on value added products from aromatic plants and encouraged the habits of women to maintain personal health and hygiene at their homes and in their surroundings; thus making them economically more self-reliant \& empowered. The beneficiaries were selected from different villages and care was taken to select appropriate number of women beneficiaries from SC/ST, backward, landless, economically weaker and unemployed women of the target areas/villages.

The knowledge provided through training will help in awareness, improvement of health, socio-economic status, capacity buildings and confidence of rural population and economically weaker sections of the society.

This project worked towards educating and training the economically weaker section of the 
rural society in the development of herbal health care products, by utilizing medicinal and aromatic plants (chiefly lemongrass and basil) for gainful employment and income generation.

Over the longer term, economic prosperity for socially deprived communities will bring about an end to discrimination based on caste.

\section{CONCLUSION}

The overall conclusion of the above study was that linkages with different segments of the target society were established and training programmes to educate and train the target group for the cultivation, processing, storage, pre and post-harvest methodology and techniques for the processing and cultivation of different aromatic plants for gainful employment were arranged.

To conclude the above study was initiated for improvement in overall quality of rural women life, change in degree of their awareness, development of their self-confidence and selfesteem and more positive view and recognition of women's economic contribution.

\section{FINANCIAL SUPPORT}

The authors gratefully acknowledge the support and funding from Department of Science \& Technology (DST), Government of India for the smooth execution of the project.

\section{ACKNOWLEDGEMENT}

Authors are also grateful to Dr. Ashok K. Chauhan, Founder President and Mr. Atul Chauhan, Chancellor, Amity University UP, Noida, India for the encouragement and research facilities.

\section{REFERENCES}

Eyben, R., and others 2008, 'Conceptualizing empowerment and the implications for pro-poor growth,'Institute of Development Studies, at the University of Sussex, Brighton.

FAO SOFA 2010-11 <http://www.fao.org/3/aat890e.pdf>

First Post, $<$ http://www.firstpost.com/business/socioeconomic-survey-three-fourth-of-rural-indiashighest-income-below-rs-5000-2325918.html> Mangla, S.M. 2000, 'Social status of women in India,'Third Concept, March, vol.14, pp. 27. Yadava, S.S. 2002, 'Educational and Socio Economic condition of Women,'Indian Journal of Social Development, Vol.1, no.2.

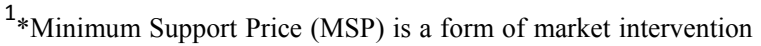
by the Government of India to insure agricultural producers against any sharp fall in farm prices. The minimum support prices are announced by the Government of India at the beginning of the sowing season for certain crops on the basis of the recommendations of the Commission for Agricultural Costs and Prices (CACP).
} 